\title{
9
}

\section{Quantifying the Stormwater Pollutant Reduction Benefits of Traditional Public Works Maintenance Practices}

\author{
Roger C. Sutherland, Robert J. Myllyoja and Seth L. Jelen
}

A management study for the Bell Branch and Tarabusi Creek Subwatershed of the Rouge River in southeastern Michigan was prepared by the Rouge River National Wet Weather Demonstration Project (NWWDP) under the guidance of the Subwatershed Advisory Group (SWAG) (NWWDP, 1997). The management study outlined several goals to help public agencies develop appropriate management practices. One of the goals was to restore impaired beneficial uses of the river by reducing pollutant loadings in stormwater. The SWAG recommended stormwater management activities that reduce or eliminate pollutants at their source such as leaf collection, catchbasin cleaning, and street sweeping which should be routinely conducted. In support of these recommendations, the City of Livonia, Michigan led an effort to evaluate a variety of maintenance and cleaning practices for catchbasins for a portion of a tributary within the subwatershed with financial support of the Rouge River National Wet Weather Demonstration Project.

\subsection{Introduction}

In 1999, the City of Livonia authorized Hubbell, Roth \& Clark, Inc. (HRC) and its subconsultant Pacific Water Resources, Inc. (PWR) to conduct a Storm Sewer Maintenance Study of Livonia's portion of the Bell Branch and Tarabusi Creek Subwatershed (HRC, 2001). The study basin has a drainage area of 923 acres (375 ha) and consists of residential, commercial and recreational land

Sutherland, R., R. Myllyoja and S.L. Jelen. 2002. "Quantifying the Stormwater Pollutant Reduction Benefits of Traditional Public Works Maintenance Practices." Journal of Water Management Modeling R208-09. doi: 10.14796/JWMM.R208-09.

(c) CHI 2002 www.chijournal.org ISSN: 2292-6062 (Formerly in Best modeling practices for Urban Water Systems. ISBN: 0-9683681-6-6) 
uses. The study included the use of the Simplified Particulate Transport Model (SIMPTM) (Sutherland and Jelen, 1998) to help evaluate the stormwater pollution reduction benefits associated with the periodic cleaning of sediment trapping catchbasins and related maintenance practices such as street sweeping. The study also involved the selection of four pilot test areas that were representative of the three land uses found throughout the watershed. These pilot test areas were monitored over an eight-month period in which the accumulation and physical/chemical characteristics of the sediment found on streets, parking lots and trapped within catchbasins were recorded. This information was used to calibrate the SIMPTM program. A representative year or average year of rainfall data constructed from an historic 40-year trace was used to simulate the pollutant reduction benefits associated with various combinations of catchbasin and street sweeping operations. Marginal cost analyses were used to identify the optimal mix of these traditional public works maintenance practices for each of the three targeted land uses.

\subsection{Selection of Pilot Test Areas}

An important aspect of the study design was the selection of pilot test areas that best represent the land use/physical characteristics that predominate throughout the study basin. Working with the best available data from the City's GIS, the location of the various storm sewer systems including catchbasins, pipes and outfalls, were mapped on recent orthophotographs. The topography data was used to subdivide the 923 -acre ( $375 \mathrm{ha})$ watershed into 21 subareas.

A reconnaissance (i.e. windshield) survey of the subareas was conducted by automobile to gather additional land use and physical characteristics data that were not currently available from other sources. This data included:

- type of surface drainage system, such as curb and gutter versus roadside swales;

- street pavement condition and texture;

- the slope along the upland stormwater flow path;

- whether the direct connection of roof drains to the gutter line existed; and

- the average dimensions of stormwater inlets including the size of the sediment storage area or sump.

Using all of this information, four representative pilot test areas were selected for monitoring the physical/chemical characteristics of the sediment found on directly-connected paved areas and trapped within catchbasins. One area was a commercial shopping center (Newburgh), two were single-family 
residential (Munger and Riverside) and one was recreational (Fox Creek). Each pilot area was relatively small with seven to fifteen sediment trapping catchbasins to be monitored. Sediment accumulation monitoring sites within each pilot area were selected and included a shopping center parking lot, two residential streets and a golf course parking lot. These monitoring sites for accumulation varied from $600 \mathrm{ft}^{2}\left(55 \mathrm{~m}^{2}\right)$ to $1500 \mathrm{ft}^{2}\left(138 \mathrm{~m}^{2}\right)$ and were paved areas directly tributary to a single stormwater inlet (i.e. catchbasin) within a given pilot area.

\subsection{Sediment Sample Collection}

The sediment sample collection program was designed as follows:

- Initial samples of street and parking lot dirt (obtained by industrial vacuum) and catchbasin sediments (obtained by soil sampler and shovel) were collected at all four sites on 9/10/99 and 9/13/99 respectively. These samples were analyzed by HRC for mechanical grain size in eight particle size groups and then recombined into three groups (called fine, medium and coarse) for RTI Laboratories to perform chemical composition analyses.

- A grab sample of standing water was collected from a downstream sump in each of the four pilot test areas on 9/13/99 before the sumps were cleaned. These samples were tested for E. coli, fluoride, chloride, nitrite, nitrate and sulfate.

- All paved surfaces were swept and all catchbasin sumps and laterals were cleaned by City staff in mid-October.

- Another grab sample of standing water was collected after cleaning on 10/14/99 from the same downstream sumps that were sampled earlier. These samples were also tested for E. coli, fluoride, chloride, nitrite, nitrate and sulfate.

- Sediment accumulations were monitored in the catchbasin sumps on $11 / 5 / 99,12 / 9 / 99,3 / 24 / 00$, and $5 / 11 / 00$. Following the monitoring on $5 / 11 / 00$, composite samples were analyzed for particle size and chemical characteristics.

- Street and parking lot dirt accumulations were monitored on $11 / 4 / 99,1 / 6 / 00,3 / 24 / 00$, and 5/16/00. A second accumulation monitoring site in each pilot area was also sampled on 3/24/00. Both of these sites were monitored for accumulation at the two residential areas on 5/16/00. After obtaining a total dry weight, the samples taken on $1 / 6 / 00$ and $5 / 16 / 00$ were analyzed for particle size and chemical characteristics. 


\subsection{Mechanical Analysis of Sediment Samples}

HRC's Structural Lab performed the mechanical analyses of the street dirt and catchbasin sediments. All work was performed in general accordance with the appropriate American Society for Testing and Materials (ASTM) test methods except where procedures were modified as required by the scope of work. Mechanical grain size analysis was performed on thirty samples and the results can be found in HRC (2001). The dry weights for each of the eight sieve fractions were summed and compared to the sample net dry weight. Weight gain/loss was noted. All testing was performed with stainless steel equipment provided by PWR. All weights were measured in metric units to three significant figures. The total dry weight for the eight fractions provided the total street dirt accumulation for that time period. After the mechanical analyses of the first, third and fifth set of samples (i.e. those collected on 9/10/99 and $9 / 13 / 99,1 / 6 / 00$, and $5 / 19 / 00$ ), fractions were recombined into three size groups for chemical analysis by RTI Laboratories. These composite samples were compiled as follows:

1. $<63$ microns $(\mu \mathrm{m})$, fine

2. 63 to $250 \mu \mathrm{m}$, medium, and

3. 251 to $6370 \mu \mathrm{m}$, coarse.

4. The fraction greater than $6370 \mu \mathrm{m}$ was discarded.

\subsection{Chemical Analysis of Sediment Samples}

The three particle size ranges documented above for the initial and third set of sediment samples were analyzed for chloride, ortho-phosphorus, total phosphorus, chemical oxygen demand (COD) and the ten stormwater metals recommended by Michigan Department of Environmental Quality (MDEQ). The final set of samples was tested for the above list of parameters along with a modified Synthetic Precipitation Leaching Procedure (SPLP) for leachable metals. The SPLP was selected over a Toxic Characteristic Leaching Procedure (TCLP) extraction because it would provide a more realistic assessment of dissolved pollutant mobility under real rainfall to runoff conditions rather than a worst case scenario. The extraction was prepared to have a $\mathrm{pH}$ of 4.4 (i.e. similar to rainfall in Livonia) using deionized water and glacial acetic acid, added to the sample at a 10:1 ratio of liquid to sample, and tumbled for an eight-hour period which is equal to the average duration of rainfall in Livonia. The $\mathrm{pH}$ and contact times were, therefore, modified from standard procedures to simulate a local rainfall event. Total and ortho-phosphorus, COD, and chloride analyses were completed on the leachate without additional preservation. The SPLP 
metals (10 MDEQ), analyses were completed on the extract generated using a mixture of deionized water and glacial acetic acid. Total metals (10 MDEQ) analyses were digested and analyzed in accordance with standard methodology.

As mentioned earlier, the two sets of four standing water samples that were collected from catchbasin sumps were tested for E. coli, fluoride, chloride, nitrite, nitrate, and sulfate.

Due to additional amounts of sample required for the SPLP leachable metals analyses, some sites required mixing composite samples by combining with unused portions of previous samples. Fine, medium, and coarse catchbasin sediment samples for the two residential sites were combined on $5 / 16 / 00$ to create a single set of representative residential area chemical characterizations. At the Riverside residential site, the fine street dirt samples from several dates were combined to form an adequately sized sample. The results of the chemical analyses are presented in HRC (2001).

\subsection{SIMPTM Stormwater Quality Model}

As stated earlier, this study used the SIMPTM (Sutherland and Jelen, 1998) stormwater quality model. The SIMplified Particulate Transport Model (SIMPTM) is a continuous stormwater quality model that can simulate the stormwater pollutant loadings and expected load reductions from best management practices (BMPs) such as street sweeping and using and cleaning sediment trapping catchbasins and manholes. SIMPTM simulates the accumulation, washoff and BMP removal of sediment and its associated pollutants. Other applications of the model have demonstrated its ability to simulate the observed pollutant loads and concentrations from gauged urban basins. These examples involve monitoring for the City of Portland, Oregon's NPDES stormwater permit (Sutherland and Jelen, 1996) and the City of Bellevue, Washington's Nationwide Urban Runoff Program (NURP) (Sutherland, 1991).

\subsubsection{Washoff and Accumulations}

SIMPTM is a continuous, self-contained stormwater quality model. It divides hourly precipitation records into rainfall events and provides monthly and annual statistics for later analysis. For each event, it forms a runoff hydrograph, used to continually simulate the capacity of the stormwater inlet hydrograph to transport available accumulated sediment and associated pollutants from paved areas using the Yalin-Einstein and Foster-Meyer equations. These equations have been shown by Ellis and Sutherland (1979) to be better than the empirically based exponential washoff used, for example, in EPA's Storm Water Management Model (SWMM). 
The model also accounts for sediment deposition, armoring, and resuspension processes. Between events, SIMPTM calculates dry deposition and resuspension processes and models scheduled cleaning of streets, parking lots, catchbasins, or maintenance hatches. Overall removals from these practices are provided by SIMPTM based upon measurable data, rather than arbitrary input by the user as most stormwater quality models require. Any excess erosion remains available for further simulation, so that actual accumulations may often exceed the equilibrium load currently assumed by many models to be a maximum limit to accumulation.

Existing accumulation equations used by other models such as U.S. EPA's SWMM work contrary to the accumulation patterns observed during many urban runoff events. While accumulated loadings on paved surfaces have been observed to be greater during times of large rainfalls (i.e. wet season), it is almost always modeled as being much less, because the rainfall washes accumulated street sediment into the drainage system. Seldom is any provision made for washon, the increase that is often observed to result when washoff from adjoining unpaved areas (e.g. landscaped areas) increases the accumulation on paved surfaces following an event. A few models require seasonal parameters to model accumulation differently during wet and dry seasons, but the season is arbitrary and seldom correlates well with rainfall depth. And furthermore, even during the wet season, the model uses the dry weather accumulation algorithms, albeit with larger values.

An illustration of the dry weather accumulation function in SIMPTM can be found in Sutherland and Jelen (1996). Traditional maximum accumulation is better considered as an equilibrium accumulation, accumulations below and degradations above tending towards the equilibrium accumulation at the same exponential rate. The underlying process of deposition balanced by removal from traffic and wind remains unchanged. Wet weather accumulations or washon from higher volume runoff events result in sediment accumulations that exceed the equilibrium accumulation level. When this occurs, the net result of dry weather that follows is a decrease or degradation in sediment accumulation not an increase as is always assumed to be the case by other models such as SWMM, STORM, SLAMM, Q-ILLUDAS, P8, and NPS to name a few.

SIMPTM has been used extensively in the Portland, Oregon area as part of surface water management and water quality management plan development since 1988. It has been used in the Seattle area several times and earlier versions were used in Anchorage, Alaska, Reno/Sparks, Nevada, and throughout urban Illinois. The United States Geological Survey (USGS) applied the model in the Dallas, Texas area and concluded that it provided the best results when compared to several other models that were tested including SWMM (USGS, 1992). For a more detailed description of SIMPTM and a discussion of how it 
was calibrated to an extensive NPDES data set collected in Portland, Oregon, please refer to Sutherland and Jelen (1996).

\subsubsection{SIMPTM Calibration}

As noted previously, the SIMPTM program has the ability to simulate the accumulation and washoff of sediments and their associated pollutants. The model calibration process generally involves the adjustments of parameter values to reproduce observed runoff volumes and pollutant loads. However, since no end-of-pipe stormwater flow and pollutant concentration data were obtained during the project, the calibration focused on reproducing the observed sediment accumulations for each of the pilot test areas during the eight-month sampling period.

It is important to note that most stormwater studies cannot afford the high cost of continuously monitoring the quantity and quality of stormwater events from small homogenous sites. As an alternative, sites representative of the land use characteristics dominant within a given drainage basin of interest can be selected and monitored for the accumulation of sediments and associated pollutants at a fraction of the cost. This information can then be used to calibrate the SIMPTM program which is then used to simulate the pollutant characteristics associated with runoff from each site of interest. This is the calibration process used on this project.

A regional calibration was attempted on a historic urban runoff water quality data set collected by the Southeast Michigan Council of Governments (SEMCOG) in 1976-1977 on a 608-acre (247 ha) industrial area in Livonia called Livonia Drain No. 22 (SEMCOG, 1978). However, the attempt was not successful since entire storm durations were not sampled and many of the physical basin characteristics needed by SIMPTM were not readily available and could not be reliably estimated.

Using the hourly rainfall data observed during the eight-month sampling period within 3.5 miles or less of the monitoring areas at the SEMCOG gauging station O-24 located near the intersection of 9 Mile Road and Farmington Road, approximately 52 runoff producing rainfall events were identified whose total depth was 16.46 inches $(418 \mathrm{~mm})$. Runoff producing rainfall events were those events that satisfied one of the three minimum depth versus time criteria:

1. 0.04 inches $(1 \mathrm{~mm})$ in one hour

2. 0.07 inches $(1.8 \mathrm{~mm})$ in three hours, or

3. 0.09 inches $(2.3 \mathrm{~mm})$ in six hours.

SIMPTM computes rainfall losses using a single-parameter exponential curve that varied with rainfall depth. Once the maximum loss was specified, the exponential rate was automatically set so that the loss matched rainfall at the 
start of an event. This rainfall loss, which depends mainly on pavement texture or condition, was set to the value recently calibrated from Portland, Oregon runoff data -0.05 inches $(1.3 \mathrm{~mm})$.

Most SIMPTM parameters involving the hydraulics of washoff and sediment entrainment were related to measurable or fairly standard quantities, and were set as part of the pilot test area characterization.

The sampling events were simulated by the model to be perfect sweeping events which means that all of the accumulated dirt was picked up since this is what occurs when a site is sampled. Therefore, a perfect sweeping event was simulated by SIMPTM on each of the days in which an accumulation sample was obtained.

With all the washoff parameters set to reasonable values observed during other calibrations, the accumulation rate and equilibrium value were varied for each of the pilot test areas until one set of numbers was found to provide the best overall match. The best overall match was determined by visually examining the model's computed sediment accumulation values (mass/area) against the observed sample weight.

A further complication occurred on the residential monitoring sites. These sites were to be swept on October 7, 1999 with no other sweeping scheduled to occur throughout the rest of the sampling period. Unfortunately, due to excessive leaf debris and a miscommunication, these residential sites were also swept on December 2, 1999 and again on March 22, 2000. During the model calibration for these pilot test areas, street sweeping parameter values (i.e. Ssmin's and Sseff's) established for a Newer Mechanical sweeping operation (Sutherland and Jelen, 1997) were used to simulate each of these three street sweeping events. The results of the street dirt calibration for all the pilot test areas are presented in Table 9.1.

Table 9.1 clearly demonstrates the ability of SIMPTM to provide reasonable estimates of the magnitude of accumulated sediments found on the pilot test areas throughout the eight-month sampling period. Keep in mind that during this time period up to 52 runoff producing rainfall events occurred which would also affect these observed accumulations. A few comments are in order. The January 6, 2000 sample collected at the Newburgh shopping center (i.e. Test Area 1-G) was not considered in the calibration since it was primarily road salt. The May 16, 2000 sample collected at the Fox Creek parking area may have been affected by the landscaping activities that were occurring immediately adjacent to the parking lot. This would explain why the observed loading was twice as great as the simulated. On the two residential sites (i.e. Munger and Riverside) during the May 2000 samplings, significant accumulation differences were observed between the $\mathrm{G}$ and $\mathrm{P}$ sites although they experienced accumulation over the same identical time period. This demonstrates the 
Table 9.1 Observed versus simulated street dirt accumulations.

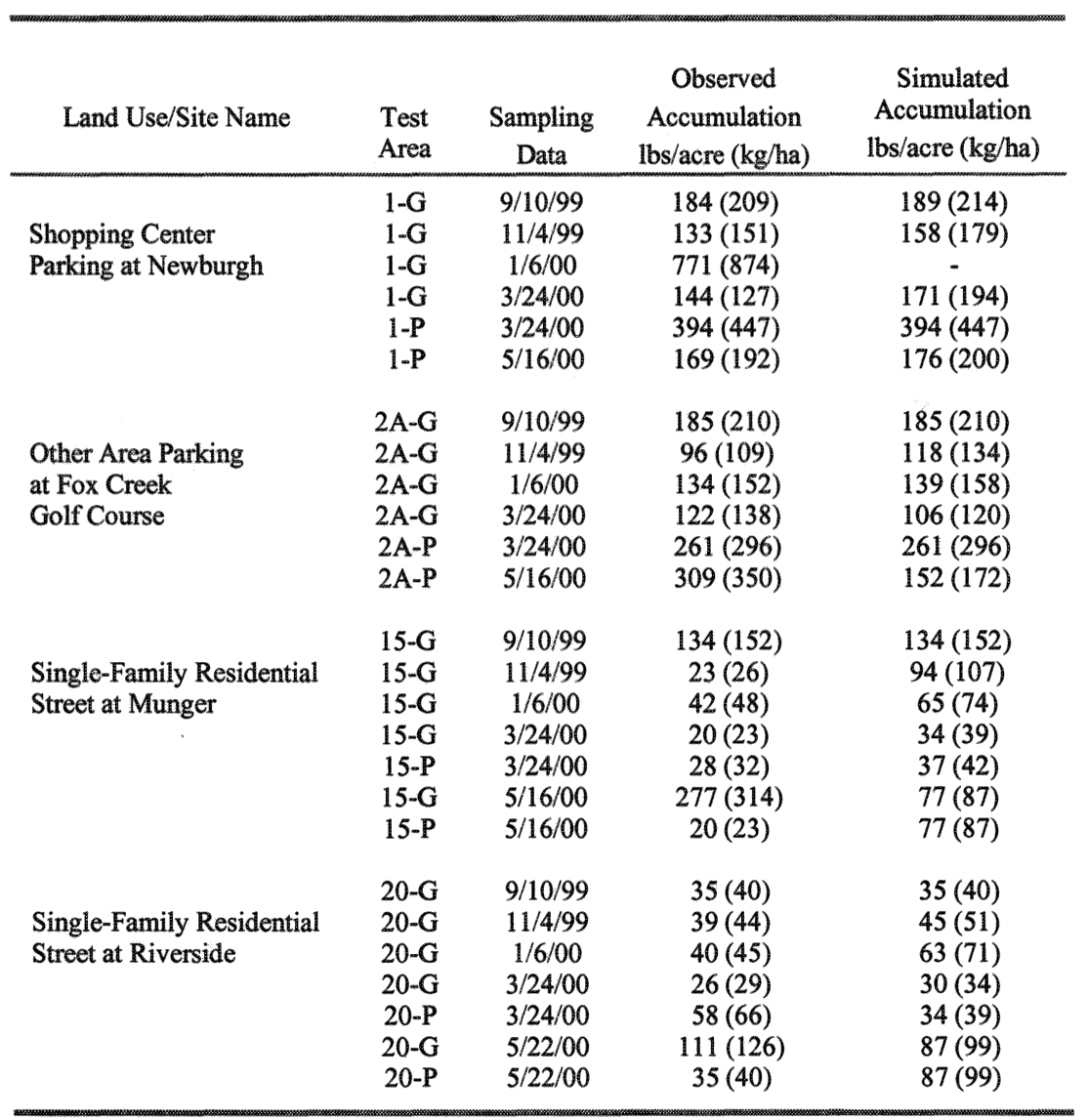

considerable variability that can exist when monitoring accumulation at sites that are almost adjacent and essentially identical. The objective of the calibration, in this case, would be to simulate an accumulation that was close to the average of both observations.

As presented earlier, the accumulation of sediments within the catchbasins located throughout the four pilot test areas was also monitored over the same eight-month period. The initial monitoring that occurred on September 13, 1999 showed a wide range of catchbasin accumulations from empty to 1.7 feet $(0.5$ $\mathrm{m}$ ) of sediment depth with average depths in the Newburgh, Fox Creek, Munger and Riverside catchbasins observed at $0.88(.27), 0.59(.18), 0.40(.12)$ and 0.25 feet $(.08 \mathrm{~m})$, respectively. All of the catchbasins were cleaned by the City on October 7, 2000. Sediment accumulations within each of the catchbasins were again monitored on 11/15/99, 1/5/99, 3/24/00, and 5/11/00. 
As part of the SIMPTM calibration, catchbasin cleaning was simulated on October 7 and the simulated accumulations in the catchbasins were compared to those average values observed near the end of the monitoring period at each of the sites. The results of the catchbasin calibration are presented in Table 9.2. This table demonstrates that SIMPTM provides reasonable estimates of the magnitude of accumulated sediment found in catchbasins over a short period of time. Note that the model is generally under-estimating these accumulations which means that any conclusions regarding the reduction in pollution due to catchbasin cleaning will be conservative, since observed accumulations appeared to be somewhat greater.

Table 9.2 Observed versus simulated catchbasin accumulations.

\begin{tabular}{|c|c|c|c|c|}
\hline Site Name & $\begin{array}{l}\text { Monitoring } \\
\text { Date }\end{array}$ & $\begin{array}{c}\text { No. of } \\
\text { Catchbasins }\end{array}$ & $\begin{array}{c}\text { Observed } \\
\text { Accumulation } \\
\text { Avg. Depth of } \\
\text { Sediment } \mathrm{ft}(\mathrm{m})\end{array}$ & $\begin{array}{c}\text { Simulated } \\
\text { Accumulation } \\
\text { Avg. Depth of } \\
\text { Sediment } \mathrm{ft}(\mathrm{m})\end{array}$ \\
\hline Newburgh & $5 / 11 / 00$ & 7 & $.06(.018)$ & $.02(.006)$ \\
\hline Fox Creek & $3 / 24 / 00$ & 8 & $.04(.012)$ & $.05(.015)$ \\
\hline Munger & $5 / 11 / 00$ & 8 & $.05(.015)$ & $.02(.006)$ \\
\hline Riverside & $3 / 24 / 00$ & 14 & $.03(.009)$ & $.01(.003)$ \\
\hline
\end{tabular}

\subsection{Average Rainfall Year Development}

Rather than simulate many runs using many years of rainfall and summarize the extensive results, a long precipitation record was processed into many precipitation events, which were then evaluated. The twelve best months were combined to synthesize an average year that was used for the annual runs to evaluate different best management practices. The development of an average rainfall year using RAINEV (a rainfall analysis program included in the SIMPTM package) has been documented several times. For a more detailed description of the development of an average rainfall year, please refer to Sutherland, Jelen and Minton (1998).

High quality, continuous hourly precipitation data for 1961 through 1998 was obtained from SEMCOG gauging station W-26 located near the intersection of Farmington Road and Highway I-96. This gauging station is located approximately 2.5 miles south of the centroid of the study's drainage basin. This hourly precipitation was processed into discrete runoff producing events using the thresholds of runoff presented earlier in the SIMPTM calibration section. These events were then summarized by the following parameters for each month of each year: 
1. number of events,

2. total duration of events,

3. total depth of events,

4. maximum hourly precipitation,

5. average intensity (i.e. total depth/total duration), and

6. average dry time preceding events.

These parameters were then analyzed graphically in a spreadsheet month by month. Each statistic for each year was compared to its average for all years. The absolute error or departure from mean was plotted by year, with emphasis on the error in total monthly depth. Months whose parameters closely approximate the long-term mean were found by searching for years where all data points (i.e. errors) were close to zero. In this manner, each of the twelve months was examined and the best month for each month was found. The hourly data for each were then combined to create a representative, average year, which was analyzed by RAINEV to generate the events used by SIMPTM in its average annual simulations.

One final modification had to occur before the representative year could be considered complete. It is important that the representative year was a representative rainfall year which means it must exclude the period of time where on the average frozen conditions exist. Therefore, we obtained and examined the long-term temperature records for the Detroit Metropolitan Airport and concluded that the average long-term freeze up period was from December 21 to February 21. Precipitation events that occurred during this period were ignored and not included in the final representative rainfall year. It is interesting to note that during the eight month monitoring period very little snowfall was observed and the typical frozen period did not occur.

The representative rainfall year for Livonia, Michigan contains 61 runoffproducing events that occur from February 27 through December 8 . These events total 24.79 inches $(630 \mathrm{~mm})$ of rainfall over a total duration of 387 hours which yields an average rainfall intensity of .064 inches/hour $(1.63 \mathrm{~mm} / \mathrm{hour})$. The average event is 0.41 inches $(10.4 \mathrm{~mm})$ in depth and lasts for approximately 6.35 hours.

\subsection{Existing Cleaning Practices}

HRC and PWR staff met with City of Livonia Public Services staff and reviewed current street sweeping and catchbasin cleaning practices. Additional information was obtained regarding cleaning frequencies and policies, road salting, leaf collection, operational and equipment costs, and disposal. 


\subsubsection{Catchbasin Cleaning}

The City of Livonia Department of Public Works uses the following catchbasin cleaning equipment:

- one Vactor 2000 - 2 to 4 years old

The City has two machines; however one is dedicated to cleaning sanitary sewers. The City's current catchbasin cleaning practices are summarized as follows:

- the City does not clean storm lines unless a problem has occurred;

- the City's current goals are to clean all public catchbasins within the City every 2.5 years on the average;

- the catchbasins are cleaned on a section by section basis (i.e. one square mile $\left(2.6 \mathrm{~km}^{2}\right)$ area at a time);

- the cleaning season is generally April to November; and

- the City does not clean catchbasins on private property.

\subsubsection{Street Cleaning}

The City of Livonia Department of Public Works uses the following street sweeping equipment:

- one Mechanical Elgin Eagle - 4 years old

- one Regenerative Air Tymco 600 - 4 years old

The equipment life was assumed to be 7 to 10 years with approximately one day of down time out of six due to maintenance and operator availability. The current street sweeping practices are summarized as follows:

- current goals are to sweep the residential areas at least 3 times each year and the major roads approximately 7 to 8 times each year. The City contracts a fourth sweeping each year following bulk leaf pickup. The Contractor uses Mobil sweepers.

- The City does not sweep the County or State roads.

- The City has a total of approximately 315 miles $(504 \mathrm{~km})$ of streets and its 36 sections are swept section by section $\left(1 \mathrm{mile}^{2} / 2.6 \mathrm{~km}^{2}\right)$.

- The City does not sweep during wet and inclement weather.

- The City does not sweep private streets, parking lots, uncurbed streets, or public parking lots.

- Typical forward operation speeds are 5-6 mph $(8-10 \mathrm{~km} / \mathrm{h})$ and slower if sediment loading conditions are very heavy.

- Parked car interference is a problem in portions of the City, mainly high school areas from late August through mid-June. None of the high schools are located within the project 
subwatershed. The City does not have an ordinance requiring residents to remove parked cars for sweeping.

- The City has a formal leaf collection program that generally occurs from the third week in October to the first week in December.

- No sanding for ice control occurs within the City unless salt cannot be obtained, which occurred once ten years ago.

- The City uses salt for ice control. Salt is only used during major ice storms at a rate of 2.34 tons per mile ( 1.26 tonnes per $\mathrm{km}$ ) to treat the major roads and residential collectors.

\subsection{BMP Analysis}

Using the calibrated model parameters from each of the three land use areas (i.e. the two residential areas were combined) and the representative rainfall year, SIMPTM was used to compute average annual Total Suspended Solids (TSS) loadings or washoffs on a unit area basis for a large array of best management practices. The practices that were evaluated included catchbasin cleaning, mechanical street sweeping, tandem sweeping (i.e. vacuum-assisted followed by mechanical), regenerative air sweeping, and high-efficiency sweeping. For a complete discussion on SIMPTM's ability to compute street sweeping operations and the sweeping model parameter values used for these simulations, please refer to Sutherland and Jelen (1997).

High-efficiency street sweepers use strong vacuums and the mechanical action of uniquely designed main and gutter brooms combined with an air filtration system that only returns clean air to the atmosphere (i.e. filters particulates to $2.9 \mu \mathrm{m}$ ). These machines sweep dry and no water is used since they do not emit dust. Schwarze Industries, Inc.'s EV series, which includes the EV-1 and EV-2, are currently the only documented high-efficiency sweepers. High-efficiency sweepers pick up and totally contain a very high portion of the fine, contaminated dirt that accumulates on streets and parking lots. For more information on high-efficiency sweeping, please refer to Sutherland, Jelen and Minton (1998).

\subsubsection{BMP Production Functions}

For the BMP simulations that were used, the frequency of the street sweeping was varied from bi-monthly to daily. The frequencies (i.e. days between sweepings) used were $61,30,15,7,4,2$, and 1 . Since the representative rainfall year was only 9 months in length (due to frozen conditions) and sweeping was 
not assumed to begin until March 15, the actual number of sweepings that corresponded to the above frequencies were $5,9,19,40,69,140$, and 282 times per year, respectively.

For the BMP simulations that were used, the frequency of catchbasin cleaning was assumed to be annual. This means the SIMPTM model began the representative year computation with the catchbasins cleaned and empty. These BMP simulations also included the simulation of no street sweeping and no catchbasin cleaning occurring throughout the year which was used to calculate how effective each of the BMPs were in removing TSS from the washoff (i.e. mass/area/year).

If one plots the relationship between effort and removal, a curve called a production function would be the result. Figure 9.1 presents the array of production functions developed for single-family residential areas found within the Livonia portion of the Bell Branch and Tarabusi Creek subwatershed. Similar figures were also developed for shopping center parking and other parking areas. Note that high-efficiency sweeping with annual catchbasin cleaning is the most effective BMP followed closely by regenerative air sweeping with annual catchbasin cleaning.

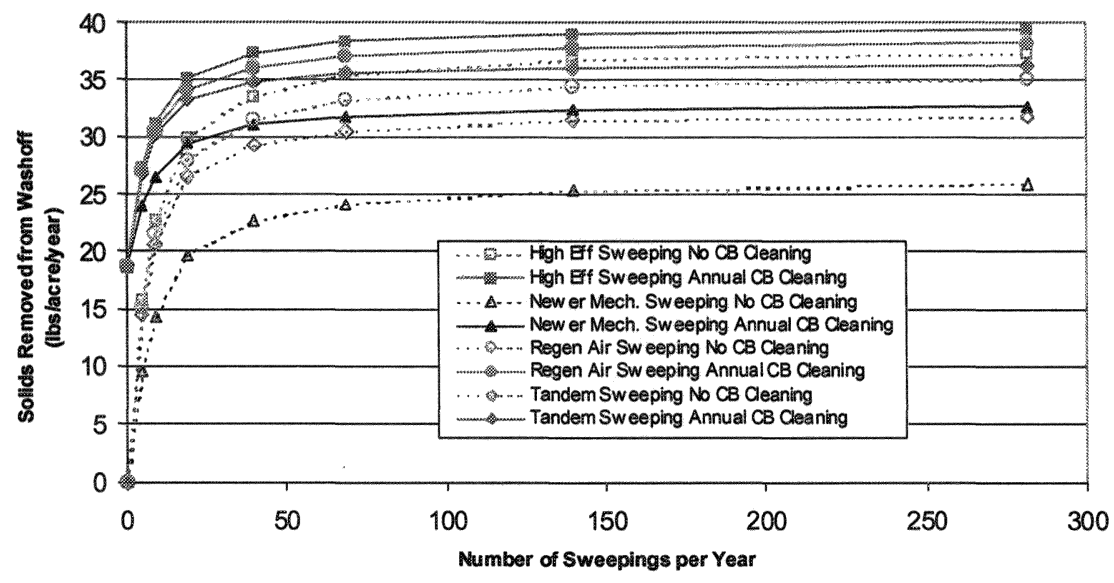

Figure 9.1 BMP production functions; single family residential in Livonia, MI.

\subsubsection{BMP Total Cost Curves}

The next step in establishing the optimal levels of the various BMPs described earlier is to establish curves that show the relationships between TSS reduction and total cost. In order to establish these relationships, we needed to estimate 
the cost of street sweeping and the cost of catchbasin cleaning and multiply the production functions by these various costs.

Fortunately, the City of Livonia tracks the cost of street sweeping and catchbasin cleaning as two separate functions. The City provided us with costs dating back to the beginning of 1998 through September 9, 2000 for both of these activities. These costs included labor, overtime, equipment and overhead associated with each activity.

Working with the 1998 and 1999 cost data since the year 2000 data was not complete, we determined that the City of Livonia currently spends an average of US $\$ 145,600$ and US $\$ 146,700$ per year on catchbasin cleaning and street sweeping respectively. The City also estimated that on an annual basis it cleaned approximately 3290 catchbasins and swept 1908 curb miles (1193 curb $\mathrm{km})$ of streets. Working with these numbers, we established the unit cost of catchbasin cleaning at US $\$ 44.25$ per catchbasin and street sweeping at US $\$ 76.90$ per curb mile (US\$123.00 per curb $\mathrm{km}$ ). The City does not currently clean or sweep private streets and parking lots. However, for the purposes of this analysis we assumed that they did and the unit costs of providing these services would be the same as those documented for the City's own operations.

As part of the analysis we did not factor in potential differences in equipment capital costs and life cycle costs. However, the equipment costs provided to us by the City did contain existing amortized capital equipment costs and existing equipment maintenance-related costs. The intent of the cost analysis was to keep it simple and see approximately how cost effective various BMPs could be in reducing pollutants entering Bell Branch and Tarabusi Creek.

The unit costs established earlier were converted to unit area costs. For catchbasin cleaning, the costs per area cleaned, for shopping center parking, other parking areas and single-family residential were US\$175 (US\$430), US\$75 (US\$185), and US\$57 per acre (US\$140 per hectare), respectively. These costs varied since we found varying densities of catchbasins as documented in the windshield surveys. For street sweeping, the cost per area swept for parking and single-family residential were US\$80 (US\$200) and US $\$ 4.50$ per acre (US\$11 per hectare), respectively. These sweeping costs were doubled for tandem sweeping operations since two pieces of equipment are operated in tandem. These costs assume that the sweeper's sweeping width is 8 feet $(2.43 \mathrm{~m})$ and the entire parking area will be swept. Only the parking lane is assumed to be swept on residential streets and the area that the residential costs are applied to is the entire residential area not just the area of residential streets.

The BMP production functions presented earlier were then multiplied by the appropriate unit area costs to create the BMP total cost curves. Figure 9.2 presents the array of total cost curves developed for single-family residential 


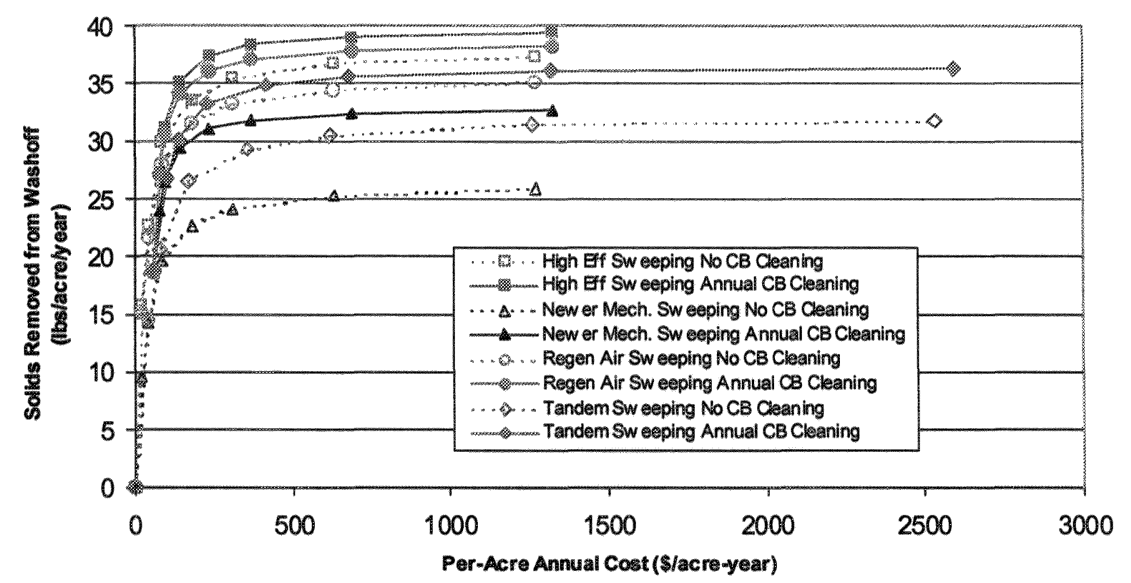

Figure 9.2 BMP total cost curves; single family residential in Livonia, MI.

areas found within the Livonia portion of the Bell Branch and Tarabusi Creek subwatershed. Similar figures were developed for shopping center parking and other parking areas.

For any given BMP, the solids removal increases as the total costs increase. Early on, any given BMP will remove solids for not much cost. As removals increase beyond this point, costs increase at a greater rate. As we move along the curve, the cost increases bring smaller and smaller marginal increases in removal until the costs become prohibitive and no more removal can occur.

Economic production theory tells us that if everything else is essentially equal, we should always operate our practices at optimal levels. Optimal levels provide for the most cost-effective removals because they consider the true cost of removing the next pound or kilogram of a given pollutant. Finding these optimal levels is the subject of the next subsection.

\subsubsection{BMP Marginal Cost Curves}

In order for one to find the optimal level for any given practice, we need to understand the relationship between solids removal and the change in cost of removing those solids. Once the cost of removing a reasonable amount of solids reaches a reasonable marginal cost, the level of effort associated with that point is considered optimum.

To assist us in determining the optimal level of effort for any given BMP, we have developed BMP marginal cost curves. These curves show the relationship between solids removal and the marginal cost of removing those 
solids. Figure 9.3 presents the single-family residential marginal cost curves developed for four different street sweeping operations by themselves and combined with annual catchbasin cleaning. Similar figures were developed for the other two land use areas all found within Livonia's portion of the Bell Branch and Tarabusi Creek subwatersheds.

\subsubsection{Optimal BMP Effort Levels}

Working with the curves in Figure 9.3, we can conclude that US\$10 per pound (US\$22 per $\mathrm{kg}$ ) of solids removed from washoff is a reasonable level of effort in relationship to the amount of solids actually removed. Note that each BMP reaches that US\$10 per pound marginal cost at varying amounts of solids removed. Those BMPs that reach the US\$10 marginal cost at the lowest removal are the least cost-effective and the ones that reach this level at the highest removal are the most cost-effective. Table 9.3 presents a listing of the optimal effort levels for the most cost-effective to the least cost-effective BMPs for single-family residential areas in Livonia.

The optimal levels of effort defined in Table 9.3 were those levels whose marginal costs were the nearest to the arbitrarily selected US $\$ 10$ value. Some of these costs exceeded US\$10 and one could argue that one should have selected the next lower level of effort. Using this logic one could argue that the optimal level of effort on single-family residential areas for high-efficiency or regenerative sweeping with annual catchbasin cleaning was approximately once every 21 days or approximately 12 times during the average sweeping season (i.e. March 15 through December 1). The assignment of optimal levels of effort is somewhat subjective and could vary from one land use area to another.

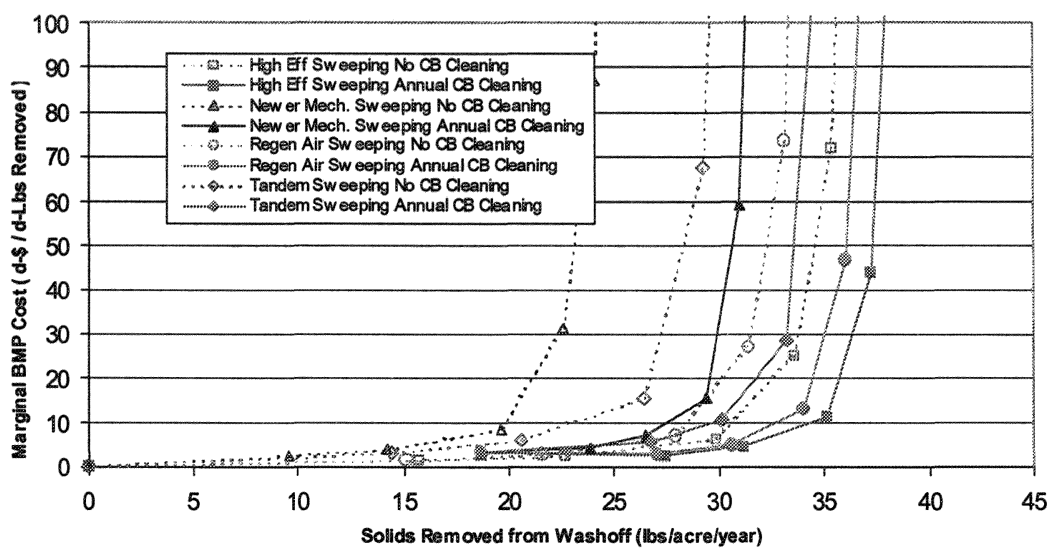

Figure 9.3 BMP marginal cost curves; single family residential in Livonia, MI. 
Table 9.3 Optimal effort levels of various BMPs on single-family residential areas.

\begin{tabular}{|c|c|c|c|c|}
\hline BMP Description & $\begin{array}{c}\text { Optimal Level } \\
\text { of Effort }\end{array}$ & $\begin{array}{c}\text { Marginal Cost } \\
\text { US\$/lb } \\
\text { removed } \\
\text { (US\$/kg } \\
\text { removed) }\end{array}$ & $\begin{array}{c}\text { Solids Removed } \\
\text { from Washoff } \\
\text { Annually } \\
\text { lb/ac (kg/ha) }\end{array}$ & $\begin{array}{c}\% \\
\text { Reduction }\end{array}$ \\
\hline HS \& annual CBC & every 15 days & $11.36(25.24)$ & $35.2(39.9)$ & 84 \\
\hline RS \& annual CBC & $\begin{array}{l}\text { every } 15 \text { days } \\
\text { (19 times) }\end{array}$ & $13.04(28.98)$ & $34.1(38.7)$ & 81 \\
\hline HS \& no CBC & $\begin{array}{l}\text { every } 15 \text { days } \\
\text { (19 times) }\end{array}$ & $6.34(14.09)$ & $29.8(33.8)$ & 71 \\
\hline TS \& annual CBC & $\begin{array}{l}\text { every } 30 \text { days } \\
\text { (9 times) }\end{array}$ & $10.59(23.53)$ & $30.1(34.1)$ & 72 \\
\hline RS \& no CBC & $\begin{array}{l}\text { every } 15 \text { days } \\
\text { (19 times) }\end{array}$ & $7.14(15.87)$ & $27.9(31.6)$ & 66 \\
\hline MS \& annual CBC & $\begin{array}{l}\text { every } 30 \text { days } \\
\quad(9 \text { times) }\end{array}$ & $6.92(15.38)$ & $26.5(30.0)$ & 63 \\
\hline TS \& no CBC & $\begin{array}{l}\text { every } 30 \text { days } \\
\text { (9 times) }\end{array}$ & $5.81(12.91)$ & $20.6(23.4)$ & 49 \\
\hline MS \& no CBC & $\begin{array}{l}\text { every } 15 \text { days } \\
\text { (19 times) }\end{array}$ & $8.33(18.51)$ & $19.6(22.2)$ & 47 \\
\hline
\end{tabular}

The results clearly show that street sweeping in combination with catchbasin cleaning could provide some very significant reductions in TSS loadings with scheduled frequencies of 15 to 30 days. This would represent a large increase in existing sweeping effort and cost since the City currently sweeps single-family residential areas four times a year and does not sweep any parking areas since they are mostly privately owned.

The marginal cost analysis showed that annual catchbasin cleaning with optimal levels of sweeping effort was more cost-effective from solids removal standpoint when compared to no catchbasin cleaning and the same level of sweeping. This conclusion was reached for all three of the land use areas studied. Once again, annual catchbasin cleaning would represent a large increase in existing cleaning effort and cost since the City currently cleans catchbasins in residential areas once every 2.5 years and does not clean catchbasins in most parking lots since they are primarily privately owned.

However, from a solids washoff standpoint, parking lots are estimated to produce extremely high loadings on a unit area basis when compared to singlefamily residential streets. Parking lot washoff was estimated to be 477 to 1090 $\mathrm{lb} /$ acre/year (541 to $1236 \mathrm{~kg} / \mathrm{ha} /$ year) compared to $140 \mathrm{lb} / \mathrm{acre} /$ year $(159 \mathrm{~kg}$ / ha/year) for single-family residential streets. So the environmental benefits of 
sweeping these parking areas nine to nineteen times per year with highefficiency or regenerative air sweepers and cleaning these catchbasins once a year appear to be quite significant. The difficult part will be finding the financial resources to pay for these increased costs.

\subsubsection{Annual Pollutant Loads}

Sediment washoff was related to washoff of other pollutants by mass fractions or potency factors assigned to each of the eight particle size groups of accumulated sediment. These are generally set from observed fractions of accumulated sediment or from observed sediment washed off during sampled events. Since no washoff data was obtained, the pollutant computations were based on the chemical analyses of the collected samples.

As discussed earlier, chemical analyses of the street dirt samples were conducted for metals, COD, total phosphorus (TP), Ortho Phosphorus and chloride (CL). It was determined that in addition to total suspended solids (TSS) the SIMPTM pollutant simulations should include COD, TP, copper (CU), and zinc $(\mathrm{ZN})$. The simulation of the total particulate fraction of each pollutant was based on the mean potency factors observed in these sediment analyses which can be found in HRC (2001).

Table 9.4 presents a summary of alternative BMP unit pollutant washoffs computed by SIMPTM for each of the three areas studied in Livonia's portion of the Bell Branch and Tarabusi Creek subwatersheds. Both existing and optimal levels of catchbasin cleaning and street sweeping are included in the table. The optimal practices referred to in Table 9.4 are for optimal water quality benefits.

Working with the unit pollutant washoffs in Table 9.4 it is estimated that sweeping every 15 days with high-efficiency or regenerative air sweepers and annual catchbasin cleaning of shopping center parking areas should reduce the annual washoff of TSS, COD TP, CU and ZN by approximately 84 to $87 \%$. In fact, sweeping other parking areas every 30 days with high-efficiency or regenerative air sweepers and annual catchbasin cleaning should reduce washoffs of these pollutants by approximately 70 to $75 \%$ annually.

The computations for single-family residential areas suggest that existing levels of sweeping reduce pollutant washoffs only 19 to $33 \%$ depending on whether the mechanical or regenerative air sweeper is being used, respectively. No benefit is being projected for catchbasin cleaning which occurs once every 2.5 years on the average. This is not necessarily true since some benefits would exist. However, it is impossible to compute a cleaning frequency of 2.5 years in a computation of only one year. It is estimated that cleaning the catchbasins every 2.5 years may provide an additional $5 \%$ reduction of these pollutants annually. The recommended sweeping levels of every 15 days with annual 
Table 9.4 Annual pollutant washoffs with optimal and existing maintenance practices.

\begin{tabular}{|c|c|c|c|c|c|c|c|}
\hline \multicolumn{2}{|c|}{ Land Use and BMP Description } & $\begin{array}{l}\text { Runoff } \\
\text { (ft/yr) }\end{array}$ & $\begin{array}{c}\text { TSS } \\
(1 \mathrm{~b} / \mathrm{ac} / \mathrm{yr})\end{array}$ & $\begin{array}{c}\mathrm{COD} \\
(\mathrm{lb} / \mathrm{ac} / \mathrm{yr})\end{array}$ & $\underset{(\mathrm{TP} / \mathrm{ad} / \mathrm{yr})}{ }$ & $\begin{array}{c}\mathrm{Cu} \\
(\mathrm{lb} / \mathrm{ad} / \mathrm{yr})\end{array}$ & $\underset{(\mathrm{lb} / \mathrm{ac} / \mathrm{yr})}{\mathrm{Zn}}$ \\
\hline \multicolumn{8}{|c|}{ C-Commercial Parking Areas } \\
\hline Existing Practice & No sweeping or inlet cleaning & 1.64 & 1090 & 7.06 & $3.08 \mathrm{E}-02$ & $3.36 \mathrm{E}-02$ & $1.09 \mathrm{E}-01$ \\
\hline Optimal Practice* & $\begin{array}{l}\text { High-eff. (EV1) sweeping ( } 15 \text { day interval; } 17 \\
\text { per year) including annual inlet cleaning }\end{array}$ & 1.64 & 144 & 0.95 & 4. 10E-03 & $4.72 \mathrm{E}-03$ & $1.57 \mathrm{E}-02$ \\
\hline Optimal Alternative* & $\begin{array}{l}\text { Regenerative air sweeping (15 day interval; } 17 \\
\text { per year) including annual inlet cleaning }\end{array}$ & 1.64 & 146 & 0.96 & 4. $14 \mathrm{E}-03$ & $5.05 E-03$ & $1.71 \mathrm{E}-02$ \\
\hline \multicolumn{8}{|c|}{ P-Recreational Parking Areas } \\
\hline Existing Practice & No sweep ing or inlet cleaning & 1.64 & 477 & 2.97 & $1.31 \mathrm{E}-02$ & $1.41 \mathrm{E}-02$ & $4.41 \mathrm{E}-02$ \\
\hline Optimal Practice* & $\begin{array}{l}\text { High-eff. (EV1) sweeping ( } 30 \text { day interval; } 8 \\
\text { per year) including annual inlet cleaning }\end{array}$ & 1.64 & 113 & 0.72 & 3.12E-03 & $3.61 \mathrm{E}-03$ & $1.17 \mathrm{E}-02$ \\
\hline Optimal Alternative* & $\begin{array}{l}\text { Regenerative air sweeping ( } 30 \text { day interval; } 8 \\
\text { per year) including annual inlet cleaning }\end{array}$ & 1.64 & 117 & 0.74 & 3.20E-03 & $3.92 \mathrm{E}-03$ & $1.30 \mathrm{E}-02$ \\
\hline \multicolumn{8}{|l|}{ S - Residential Areas } \\
\hline Worst Case & No sweeping or inlet cleaning & 0.57 & 42 & 0.27 & $1.18 \mathrm{E}-03$ & $1.39 \mathrm{E}-03$ & $4.59 \mathrm{E}-03$ \\
\hline Existing Practice & $\begin{array}{l}\text { New mechanical sweeping ( } 75 \text { day interval; } 4 \\
\text { per year) including no inlet cleaning }\end{array}$ & 0.57 & 33.4 & 0.22 & $9.36 \mathrm{E}-04$ & $1.12 \mathrm{E}-03$ & $3.72 \mathrm{E}-03$ \\
\hline Alternative Existing & $\begin{array}{l}\text { Regenerative air sw eeping ( } 75 \text { day interval; } 4 \\
\text { per year) including no inlet cleaning }\end{array}$ & 0.57 & 28.3 & 0.18 & 7. $92 \mathrm{E}-04$ & $9.62 E-04$ & $3.23 \mathrm{E}-03$ \\
\hline Optimal Practice* & $\begin{array}{l}\text { High-eff. (EV1) sweeping ( } 15 \text { day interval; } 17 \\
\text { per year) including annual inlet cleaning }\end{array}$ & 0.57 & 7.94 & 0.05 & $2.24 \mathrm{E}-04$ & $2.77 \mathrm{E}-04$ & $9.40 E-04$ \\
\hline Optimal Alternative*k & $\begin{array}{l}\text { Regenerative air sweeping ( } 15 \text { day interval; } 17 \\
\text { per year) including annual inlet cleaning }\end{array}$ & 0.57 & 8.94 & 0.06 & $2.49 \mathrm{E}-04$ & $3.23 \mathrm{E}-04$ & $1.11 \mathrm{E}-03$ \\
\hline Notes: & $\begin{array}{l}\text { REPYR rainfall depth total is } 24.79(630 \mathrm{~mm}) \\
\mathrm{kg} / \mathrm{ha} / \mathrm{yr}=1.134 \mathrm{x}(\mathrm{lb} / \mathrm{ac} / \mathrm{yr}) \\
\mathrm{m} / \mathrm{yr}=.303 \mathrm{x}(\mathrm{tt} / \mathrm{yr})\end{array}$ & & & & & & \\
\hline
\end{tabular}


catchbasin cleaning and using either a high-efficiency sweeper or a regenerative air sweeper is estimated to annually reduce pollutants by $76 \%$ to $81 \%$, respectively in residential areas.

Chloride levels could not be easily modeled because it is not a particulate based pollutant. However, we wanted to obtain some information on chloride levels through various seasons in different land uses. The average chloride levels found in the accumulated sediment were 2.7 times higher in the recreational parking area than the average of the residential areas and 240 times higher in the commercial parking area. As expected, these chloride concentrations were much higher during the January monitoring. Unfortunately, although research in this topic is expanding, we are not aware of a cost-effective, nontoxic alternative for deicing of commercial paved areas at this time.

Concentrations of ortho-phosphorus and all of the metals, except lead, were higher in the catchbasin sediment than the street dirt while chloride, COD, and total phosphorus levels were higher in the street and parking lot dirt. The catchbasin sediment fines (i.e. $<63$ microns) had the highest concentrations of the three fractions for all metals except mercury, where it was almost evenly distributed. The street dirt fines had the highest concentrations of the three fractions for all metals except for lead and barium. The lead concentrations were considerably higher in the medium fraction (i.e. 63 to 250 microns).

\subsection{Conclusions and Recommendations}

This study resulted in numerous conclusions and recommendations (HRC, 2001). The most important conclusions are summarized below.

\subsubsection{Public Parking Lots and Streets}

It appears evident that an increase in street sweeping efforts for residential streets would reduce TSS loadings. Because the model calibration was based on eight months of limited monitoring of three specific land uses, the results should be confirmed before implementing the optimal cost-effective practices. Public streets serving other land use areas such as industrial areas and major arterial roads were not monitored. Nevertheless, we expect that all other sources (i.e. public streets in other land use areas and major arterial roads) will provide much higher loadings than the residential areas monitored. Therefore, even an intermediate increase in street sweeping effort for public streets will be beneficial to water quality of the Bell/Tarabusi Branch of the Rouge River. 
We recommended that the City of Livonia Department of Public Works investigate methods to increase funding for their street sweeping and catchbasin cleaning efforts. Street sweeping was more cost-effective than catchbasin cleaning and should, therefore, be a priority. We also recommended that the City increase the street sweeping frequency to monthly (i.e. doubling of the effort) for all public roads from April to November of each year which should increase TSS removal at residential areas from the current $36 \%$ to $51 \%$ assuming that a regenerative air sweeper is being used. We also recommended that the City utilize regenerative air sweepers until an in-depth study of long-term equipment capital and maintenance cost could be conducted.

The optimal frequency of street sweeping represents the level of effort that provides the highest TSS washoff reduction for acceptable increases in cost. In other words, at more frequent than optimal levels, the additional TSS washoff reduction is not worth the additional expenditure. Any increase in effort up to the optimal level will be beneficial. In fact, the first increase in effort over existing conditions will provide the most cost-effective pollutant reduction. Although the optimal level of effort is the most costly that can be economically justified, it still may not be economically feasible. However, since maintenance practices remove pollutants at the source before they can become soluble they are by their nature more cost-effective than end-of-the-pipe controls.

The model evaluated the optimal cost-effective mix of practices in representative medium-density residential areas within the study tributary. Assuming that the residential areas monitored were representative of the entire City, we have provided the optimal cost-effective mix of practices for all residential areas. We recommended that the City should consider confirming these results as well as monitoring other source areas. We recommended that an additional year of monitoring to include the following:

- confirming the loading rates at the current pilot test areas;

- monitoring additional public streets and major arterial roads;

- continuing catchbasin accumulation monitoring of the previous residential pilot test areas;

- conductingperformance tests of the City's existing street sweepers and a high-efficiency sweeper; and

- conducting an in-depth study of the long-term equipment capital, life cycle, and maintenance costs.

An additional year of catchbasin accumulation monitoring will provide information on the average rate of sediment accumulation and the length of time it takes for the sumps to reach the critical breakthough point of $60 \%$ of depth (i.e. ability to trap additional sediment is minimal beyond this point). Recommendations for optimal catchbasin cleaning frequencies could then be provided. 
Once the additional accumulation data is collected and the City's sweeping equipment is tested, this analysis can be revised with better long-term equipment and maintenance costs. The results will yield accurate estimates of optimal sweeping and catchbasin cleaning frequencies and the most appropriate sweeping equipment for all significant public roads and parking areas in the City.

\subsubsection{Private Parking Lots and Streets}

We recommended that the City investigate the feasibility of a city-wide program to require street sweeping and catchbasin cleaning within private land use areas. Annual TSS loadings in commercial parking areas were three times higher than residential streets on a mass per area basis. The significant pollutant removal benefits of street sweeping and catchbasin cleaning within commercial parking lots has made this land use a priority over the other areas monitored.

We recommended that the City should consider developing a stormwater utility or revising existing ordinances to require BMPs for private land use areas. Due to the relatively low loadings and toxicity of the recreational parking lot dirt, these areas should be less of a priority at this time.

We recommended that monitoring of private land use areas such as an additional commercial site and two industrial sites should be completed for a duration of one year. Once this additional monitoring is completed and the data analyzed, the City could then determine the cost of optimal street sweeping and catchbasin cleaning practices in privately maintained areas.

\subsubsection{General}

One of the objectives of this study was to assess how effective the SIMPTM program was in providing a means for communities and agencies to assess their stormwater quality problems and to evaluate the cost-effective public works practices needed to solve them. We concluded that the model was very useful. However, because of differences in rainfall, land uses, imperviousness, pavement condition and texture, topography, and other physical characteristics, the model should only be applied to the specific characteristics that exist within a given study area. The results of this study may not apply to all Michigan urban watersheds. With this in mind, we have developed several additional recommendations for future SIMPTM applications.

As mentioned earlier, we recommended that the City expand its monitoring efforts to include major arterial roads, industrial sites, and other commercial sites such as gas stations. The monitoring sites should be watershed specific and should be representative of other similar land uses in the study watershed or the City. Several sites should also be monitored within each pilot test area to insure representative sampling. 
Although leachable or dissolved metals were not found to make up a large percentage of the total metals observed in the accumulated street dirt, they probably represent a large portion of the metals that are being transported by stormwater and monitoring of these parameters using a comparable modified procedure should be continued for the various sediment sizes. Levels of these forms of metals may be higher for major arterial streets and industrial sites. It is the leachable or dissolved metals found throughout the entire street dirt heap, in association with the finest fraction of particulate pollutants, that are the most difficult to remove, the most mobile, and therefore the most toxic to the environment.

\section{References}

Ellis, F.W., and R.C. Sutherland, 1979. An Approach to Urban Pollutant Washoff Modeling, Proceedings, International Symposium on Urban Storm Runoff, Lexington, Kentucky.

Hubbell, Roth \& Clark, Inc., 2001. Storm Sewer Maintenance Study, Prepared for the City of Livonia, Michigan.

Rouge River National Wet Weather Demonstration Project, 1997. Management Study for the Bell Branch and Tarabusi Creek, Work Plan No. URBSW6, Wayne County, Michigan.

Southeast Michigan Council of Governments, 1978. Urban Stormwater: Its Quality and Management, Detroit, Michigan.

Sutherland, R.C., 1991. Modeling of Urban Runoff Quality in Bellevue, Washington, Using SIMPTM. Proceedings, Nonpoint Source Pollution: The Unfinished Agenda for the Protection of our Water Quality, State of Washington, Water Research Center, Report 78.

Sutherland, R. and S.L. Jelen. 1996. "Sophisticated Stormwater Quality Modeling is Worth the Effort." Journal of Water Management Modeling R191-01. doi: 10.14796/JWMM.R191-01.

Sutherland, R. and S.L. Jelen. 1997. "Contrary to Conventional Wisdom, Street Sweeping Can be an Effective BMP." Journal of Water Management Modeling R195-09. doi: 10.14796/JWMM.R195-09.

Sutherland, R.C., and S.L. Jelen, 1998. Users Manual Version 3.2 Simplified Particulate Transport Model, SIMPTM, Pacific Water Resources, Inc., Beaverton, Oregon.

Sutherland, R., S.L. Jelen and G.R. Minton. 1998. "High Efficiency Sweeping as an Aternative to the Use of Wet Vaults for Stormwater Treatment." Journal of Water Management Modeling R200-18. doi: 10.14796/JWMM.R200-18.

USGS, 1992. Calibration and Users Guide for the Simplified Particulate Transport Model (SIMPTM), Water Resources Division, Austin, Texas. 